\title{
Drake University \\ College of Business and Public Administration \\ Des Moines, IA 50311, USA
}

\section{POSITION:}

A tenure track position in actuarial science in the College of Business and Public Administration, to begin August, 2004, pending final budgetary approval. Rank and salary based on qualifications.

\section{DUTIES:}

Teach six courses per year; recruit, advise, and place students; conduct scholarly research; and serve the University and the profession.

\section{QUALIFICATIONS:}

Ph.D. in actuarial science or a related area along with Associateship or Fellowship in the CAS or SOA is preferred. Candidates with lesser qualifications will be considered if there are compensating factors.

\section{APPLiCATIONS:}

Submit a curriculum vitae and arrange for three letters of reference to be sent to Professor Stuart Klugman, F.S.A.; CBPA; Drake University; Des Moines, IA 50311. Applications will be accepted until the position is filled. Drake University is an equal opportunity/affirmative action employer and actively seeks applications from women and minority group members who are qualified for this position.

Stuart Klugman, F.S.A., Ph.D.

Principal Financial Group Professor of Actuarial Science Drake University Des Moines, IA 50311

515-271-4097

E-mail: stuart.klugman@drake.edu 